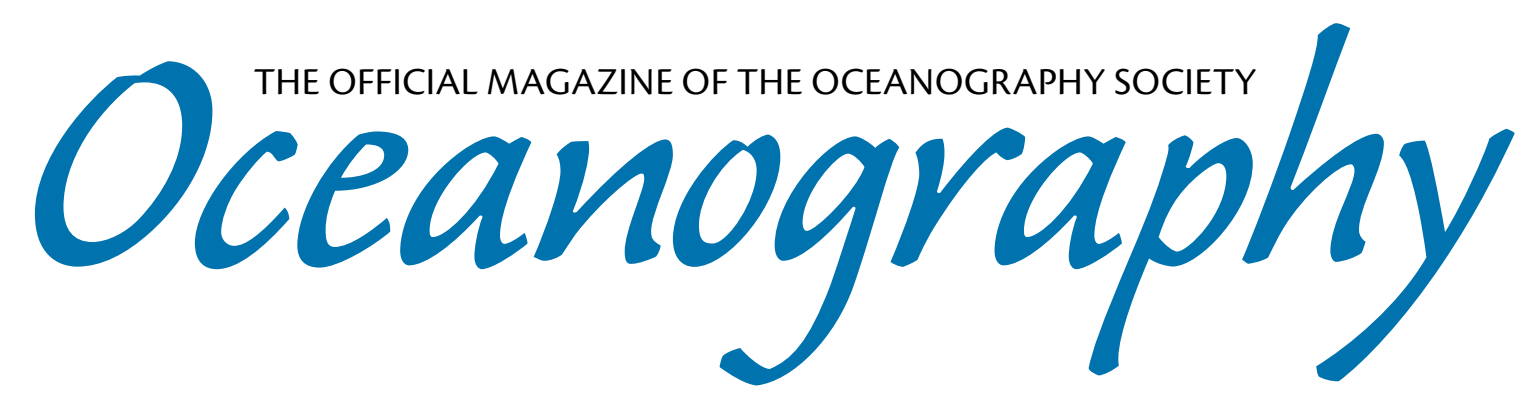

CITATION

Ramp, S.R., and T.Y. Tang. 2011. A history of Taiwan/US oceanographic research in the South China Sea. Oceanography 24(4):16-23, http://dx.doi.org/10.5670/oceanog.2011.90.

DOI

http://dx.doi.org/10.5670/oceanog.2011.90

COPYRIGHT

This article has been published in Oceanography, Volume 24, Number 4, a quarterly journal of The Oceanography Society. Copyright 2011 by The Oceanography Society. All rights reserved.

USAGE

Permission is granted to copy this article for use in teaching and research. Republication, systematic reproduction, or collective redistribution of any portion of this article by photocopy machine, reposting, or other means is permitted only with the approval of The Oceanography Society. Send all correspondence to: info@tos.org or The Oceanography Society, PO Box 1931, Rockville, MD 20849-1931, USA. 


\section{A History of \\ Taiwan/US Oceanographic Research in the South China Sea}

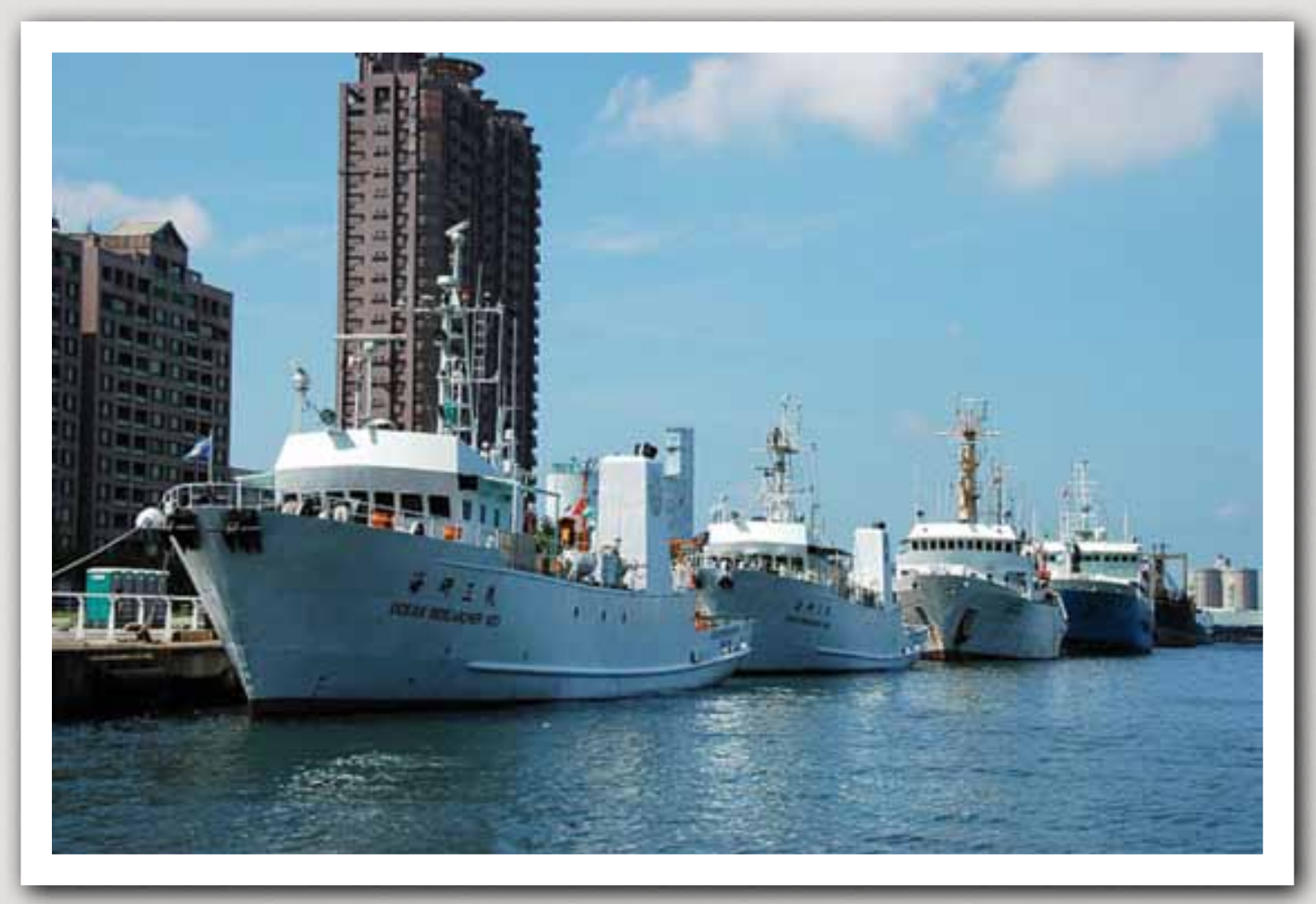

Figure 1. A rare photograph of the Taiwanese research fleet docked together in the Port of Kaohsiung, Taiwan. From front to back, Ocean Researcher 3, Ocean Researcher 2, Ocean Researcher 1, and Fisheries Researcher 1. Photo credit: Ya-Chan Chang 
INTRODUCTION AND

\section{BACKGROUND}

Oceanography is a relatively new field in Taiwan. As a maritime nation surrounded by water, the societal need to understand the seas has long been recognized. From the path of the Kuroshio to the path of the ferocious typhoons that pound the island with devastating regularity, understanding ocean processes and air-sea coupling reaps clear benefits for scientists and citizens alike. An accurate path prediction for a single typhoon may save hundreds of lives and millions of dollars in property damage. Driven by the need to understand the neighboring seas, Taiwan has embarked on an ambitious program to develop the human resources and physical infrastructure needed to conduct ocean research of the highest caliber.

Today's senior professors are the firstgeneration oceanographers of Taiwan. Because postgraduate infrastructure was lacking during their educational years, they by necessity earned their PhDs abroad. Most chose to pursue their education in the United States, which was all too happy to have these talented, hard-working students. This cross-cultural pollination held many benefits down the road, including the life-long alliances that professor/student relationships build. While most of the new graduates returned to Taiwan, many chose to remain in the United States where they established successful careers as leaders in many prominent American oceanographic institutions. Those who returned became the leaders of modern oceanographic research in Taiwan. They established first-rate graduate programs at their own universities, where today's Taiwanese students receive educations on par with many available in the United States. A perquisite of this process for future collaborators is that they all became fluent in English, relieving Americans of the burden of trying to learn Chinese, and greatly facilitating the team-building process.

Research vessels are, of course, essential to successful oceanographic research programs. Taiwan's old survey Yang-Ming was the first ship to see extensive use, conducting many surveys of the Kuroshio. It was replaced in 1960 by R/V Chiu-Lien, which was leased from the US Navy and conducted the first surveys in the South China Sea (SCS). Following three decades of ship construction, several modern research vessels now ply the waters around Taiwan, including Ocean Researcher 1,
Tropical Atmosphere Ocean (TAO) moored array and the 1998 South China Sea Monsoon Experiment (SCSMEX) that included many other international scientists as well.

Research efforts in the South China Sea made a quantum leap in the late 1990s and 2000s when the US Office of Naval Research became involved in a serious way. This association all began in a banquet room in Taipei in 1998, when a small delegation from the United States met with the senior ocean leadership in Taiwan at that time, with no more than 10 or 12 people in the room. One big advantage of having a small leadership group is the ability to make decisions and move quickly. The United States proposed to partner with Taiwan to do a large field experiment on the acoustic

\section{...THE TWO NATIONS, TAIWAN AND THE UNITED STATES, HAVE BEEN TRULY EQUAL PARTNERS... THE RESULT HAS BEEN TO RAPIDLY PUSH BACK THE FRONTIERS OF KNOWLEDGE IN THE REGION FOR THE BENEFIT OF ALL.}

the sister-ships Ocean Researcher 2 and 3, Fisheries Researcher 1, and several naval vessels (Figure 1). The new, state-ofthe-art Ocean Researcher 5 is currently under construction and scheduled for launch in 2012. These vessels have been key enablers in many cooperative research programs between the United States and Taiwan. The earliest of these programs was the mid-1980s Tropical Ocean/Global Atmosphere (TOGA) effects of the shelf/slope front near the continental shelf break in the northeastern SCS. After the first of many fine banquets enjoyed in Taiwan, the Taiwan side said, "We're in," glasses were raised, and indeed they were. The Asian Seas International Acoustics Experiment (ASIAEX) in Taiwan was born, and it became the first of many successive, and successful, Taiwan/US collaborations in the South China Sea. 
ASIAEX was the largest equipment mobilization that the Woods Hole Oceanographic Institution (WHOI) had ever done up to that time, filling up an entire warehouse on the Kaohsiung waterfront. The warehouse is now gone, a casualty of the rapid cleanup of the Port of Kaohsiung to diversify the economy and attract tourism. Repeat visitors are often amazed at the rate of change in Taiwan in as little as one year's time. A decade ago there was no High-Speed Rail, no Taipei 101, no Kaohsiung Metro Rail, no Dream Mall, no Kaohsiung art center, the Grand Hi-Lai Hotel had just been completed, and the Love River was not a place where you would want to spend time. Today, visitors take all of these things for granted, as if they had been there forever.

Alas, the ASIAEX scientists went to sea and no shelf/slope front was found. Serendipitously however, something much more exciting was discovered in the form of the world's largest highfrequency nonlinear internal waves. Scientists quickly realized that these waves were a significant source of acoustic variability. The data were tantalizing but incomplete: the wave arrivals were observed, but there were no observations of wave generation or propagation across the deep basin. Furthermore, the observations during one month in spring revealed nothing about wave arrivals in other seasons. But curiosity had been raised, and several joint followon experiments were planned. The first of these experiments was the 2005-2006 Windy Islands Soliton Experiment/ Variability Around the Northern South China Sea (WISE/VANS) program, also sponsored by the US Office of Naval Research (ONR) and the National
Science Council (NSC) of Taiwan.

Like its follow-on, the name reflects the effort of the two countries, WISE for the United States and VANS for Taiwan. This experiment obtained a full year's observations, but still only lightly sampled the wave-generation region. The Nonlinear Internal Waves Initiative/ South China Sea Ocean Prediction Experiment (NLIWI/SCOPE) during spring and summer 2007 followed the WISE/VANS experiment (Figure 2). NLIWI/SCOPE supported a big increase in the modeling effort, and brings us up to the present with the Internal Waves in Straits Experiment (IWISE) that took place during spring and summer 2011. Other major programs sprang up in parallel to the internal waves series. The Quantifying, Predicting, and Exploiting Uncertainty (QPE) experiment took place northeast of Taiwan during 2008-2009, and the Impact of Typhoons on the Ocean in the Pacific (ITOP) program is still underway.

All these programs have one thing in common, which is that the two nations, Taiwan and the United States, have been truly equal partners. Both sides have contributed scientists, research vessels such as R/V Melville (Figure 3), equipment, resources, and graduate students, and meetings and symposia have been held in both countries and authorship shared on the final publications. Working side by side under oftendifficult conditions, life-long friendships have formed (Figure 4). The graduate students from ASIAEX are now the principal investigators for IWISE and ITOP. The result, as described in greater detail below, has been to rapidly push back the frontiers of knowledge in the region for the benefit of all.
A COLLABORATIVE THREAD

As an example of how the Taiwan/United States research alliance has grown and prospered over the years, some results from the internal wave programs cited above are described below in greater detail. This is not to say that these programs are more important than any others, but rather to illustrate how these collaborations have developed over time. More detailed scientific results from all the major programs are presented in other papers in this issue.

Internal Waves and Tides Most of the high-frequency energy in the SCS originates with the barotropic tide that enters the SCS via Luzon Strait and flows southwest through the sea (Ye and Robinson, 1983; Mazzega and Bergé, 1994). The tidal flux through the strait is one of the largest in the world and results in enormous barotropic to baroclinic energy conversion (Niwa and Hibiya, 2004; Jan et al., 2008) as the tide flows over two ridges and around islands via a system of shallow sills and passages. The result is the complicated and highly energetic internal tides and high-frequency nonlinear internal waves (NLIWs) that have now been the subject of a decade of joint study. The problem can be loosely divided into generation, propagation, and shoaling/dissipation, although these processes were not studied in that order. The waves were first noticed in the far field, and teams

\section{Steven R. Ramp (sramp@solitonocean.} com) is President and CEO, Soliton Ocean Services, Inc., Carmel Valley, CA, USA. Tswen Yung Tang is Professor, Institute of Oceanography, National Taiwan University, Taipei, Taiwan. 


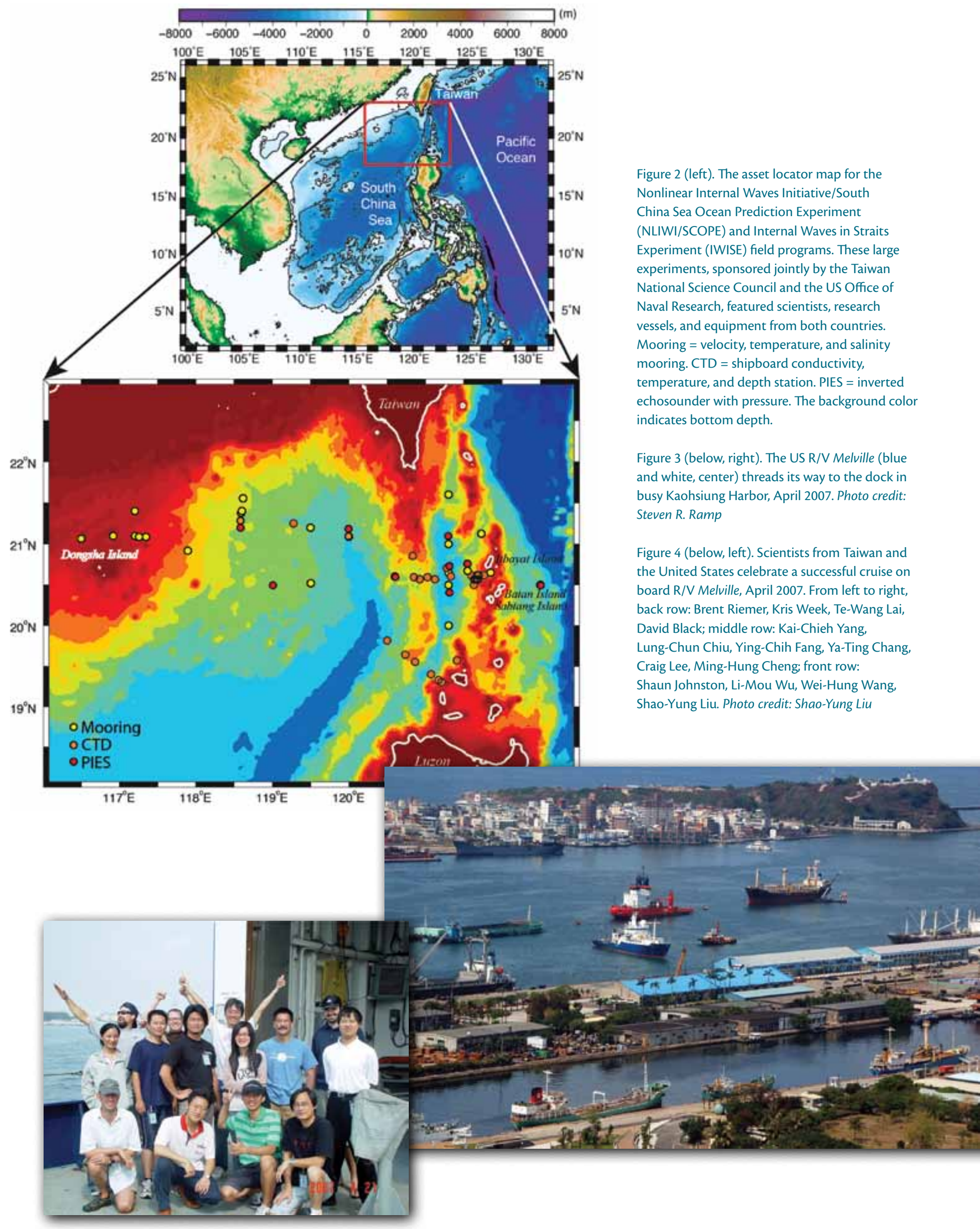


of investigators then worked backward toward the sources from there.

A heuristic discussion of the problem being studied might go something like this: The barotropic tide in Luzon Strait, which is mixed-diurnal dominant with up the slope where they split, overturn, create trapped cores, and refract around Dongsha Atoll. Once they are up on the continental shelf, the depression waves are transformed into elevation waves when the upper-layer thickness exceeds
SURELY ONE OF THE MOST DESIRABLE FUTURE PROJECTS WOULD BE A TRULY INTERDISCIPLINARY PROCESS STUDY ON THE IMPACTS OF [NONLINEAR INTERNAL WAVES] ON THE BIOLOGY, CHEMISTRY, AND
GEOLOGY OF THE SOUTH CHINA SEA.

an extreme fortnightly envelope, generates internal tides of varying strength as it flows over the shallow eastern (Lan-Yu) ridge. The result varies as a function of bottom slope, Froude number, and the excursion parameter, and ranges from very weak internal tides at neap tide to large, steep, already quite nonlinear internal tides at spring tide. The internal tide interacts in some complex way with the western (HengChun) ridge, which is deeper than the eastern ridge in the south but shallower in the north. Once clear of the ridges, the internal tides propagate freely through the deep (> 3,500 $\mathrm{m}$ ) basin, steepening as they go under the competing effects of nonlinearity and rotational dispersion. By the time they start to "feel" the bottom once again over the Chinese continental slope, the strongest tides have already spawned packets of highfrequency nonlinear internal waves, solitary waves, and solitons. Things then get really complicated as the waves run the lower-layer thickness. West of the transformation point, the waves are largely unstudied for political reasons and because the extremely high fishing effort makes moored observations impossible. The waves must ultimately be dissipated in shallow water near China, but to date we can study this process only by analogy with other areas such as the Middle Atlantic Bight.

There are now at least 30 references to support this chain of thought. The SUNTANS numerical model suggests at least two sources on the eastern ridge, one favoring semidiurnal processes and the other diurnal (Zhang et al., 2010). A comparison of inverted echosounder data with stability theory demonstrated the essential inclusion of rotation in the problem (Farmer et al., 2009). A year's worth of moored observations in the deep basin showed how the waves evolved from weakly nonlinear in the eastern basin to well-defined packets of NLIWs in the western basin (Ramp et al., 2010). Several investigators have noted that weaker solitary waves arrived alternately with stronger packets composed of several waves (Ramp et al., 2004, 2010; Lien et al., 2005; Alford et al., 2009; Farmer et al., 2009). This behavior has been attributed to multiple sources (Zhang et al., 2010), diurnal inequality (Farmer et al., 2009), and differing physics on the flood and ebb tide in Luzon Strait (Ramp et al., 2010; Zhang et al., 2010). NLIWs do not form in winter, due to insufficient stratification both at the generating ridges and along the propagation path (Shaw et al., 2009; Ramp et al., 2010). The energy in the waves is enormous (Lien et al., 2005; Chang et al., 2006; Klymak et al., 2006) and results in the highest dissipation rates ever observed when the waves shoal (St. Laurent, 2008). The waves are mostly mode-1 depression waves, although mode- 2 waves are sometimes observed over the Chinese continental slope, especially in winter when the stratification is unfavorable for mode-1 (Yang et al., 2009). Nevertheless, this picture remains very general, and the details remain to be discovered, most especially the threedimensional aspects of the problem.

\section{Impacts on Other Disciplines}

The ASIAEX program was designed from inception with understanding the acoustic impacts of coastal circulation in mind. Once the data were obtained, the analysis focus shifted from mesoscale fronts to the high-frequency internal waves and their impact on acoustic propagation. The results were groundbreaking and somewhat counterintuitive-distant sources were often heard better when the waves were present than when they were not (Chiu et al., 2004; Duda et al., 2004). 
This phenomenon was due to a vertical redistribution of acoustic energy by the large internal waves and solitons, which transferred energy from the low to intermediate modes that spanned the entire water column. The results have practical applications in the marine sonar world.

During ASIAEX, a SeaSoar towed profiler equipped with a fluorometer and transmissometer (Gawarkiewicz et al., 2004) showed enormous sediment resuspension taking place over the upper continental slope. This occurrence was speculated to be due to the incoming internal solitons, which create strong bottom currents starting at depths of $1,000 \mathrm{~m}$ or more. Subsequent surveys of the region with an EK500 echosounder yielded one of the most fascinating new discoveries to date-the existence of huge sand waves over $16 \mathrm{~m}$ tall on the continental slope between 160 and $600 \mathrm{~m}$ depth (Reeder et al., 2011;

Figure 5). The strong bottom currents induced by the high-frequency internal waves most likely form these fascinating features. While the geographical extent of these undersea dunes is unknown, it is reasonable to assume their scale is similar to the along-slope extent of the waves themselves. This singular habitat may have unique benthic communities associated with it, as yet unexplored.

Because NLIWs have regions of strong downwelling ahead of the wave and strong upwelling behind the wave that remain coherent over large distances, it is reasonable to expect the waves to have some influence on primary production (Figure 5). Most of the evidence to date, however, has been anecdotal. Shipboard observers have noticed flocks of birds following along behind the waves, and pods of beaked whales as well (Moore and Lien, 2007). There have been no focused studies to date attempting to quantify these observations.

\section{TROPICAL CYCLONES}

In the South China Sea, summer tropical cyclones and typhoons are frequent. They come mostly from the Pacific Ocean, with fewer from the Indian Ocean or spun up locally. Though mostly confined by shallow peripheries, the typhoon-induced SCS response still retains essential open-ocean characteristics such as a cold wake and trailing clockwise inertial oscillations (Price, 1981; Price et al., 1994). The combined effect of upwelling and vertical mixing induced by typhoons produces cold patches with surface temperatures several degrees cooler than the ambient waters. The consequent adjustment between wind forcing and Earth's rotation produces the clockwise inertial motions. Typically, in the open ocean,

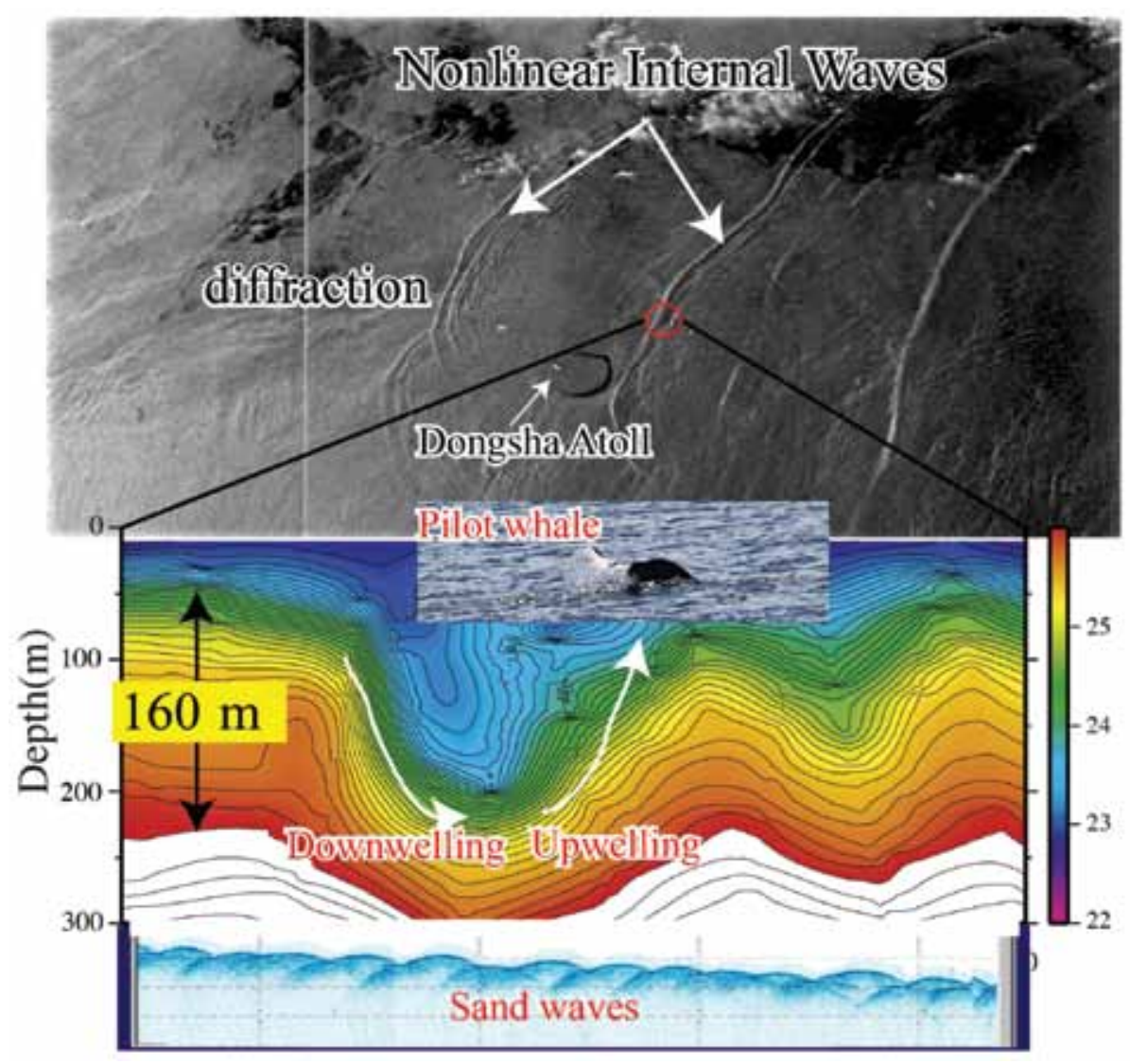

Figure 5. A composite illustration showing several interdisciplinary aspects of large-amplitude, highly nonlinear internal waves in the South China Sea. The convergent and divergent surface currents forced by the waves create regions of rough and smooth water, respectively, which are seen as the bright and dark bands in the black and white satellite synthetic aperture radar image. The waves are diffracted around Dongsha Atoll and interact in the lee of the island. Strong bottom currents scour the bottom and create sand waves up to $16 \mathrm{~m}$ tall. Regions of strong downwelling ahead of the wave and upwelling behind the wave mix the surface waters and fuel regions of high biological productivity. Pilot whales have been observed in the lee of the lead (largest amplitude) wave. The waves in both images are propagating west-northwest (toward the left). Figure courtesy of Ming-Huei Chang, National Taiwan Ocean University. Sand wave image provided by Barry Ma, APL/UW 
the sea surface temperature (SST) drop caused by typhoons could be as much as $5-6^{\circ} \mathrm{C}$ but rarely exceeds $6^{\circ} \mathrm{C}$. The cold wake and inertial motions persist for about one week.

Some outstanding characteristics of the ocean's response to a typhoon were explored during the South China Sea Monsoon Experiment (SCSMEX), a multi-institutional, multidisciplinary, and multinational program where American and Taiwanese scientists played important roles. Observationally, sea surface cooling in the northern SCS induced by Typhoon Kai-Tak during July 2000 ranged up to $9^{\circ} \mathrm{C}$ in the cold wake (Lin et al., 2003a; Tseng et al., 2010). The larger-than-normal temperature drop owes its occurrence to slow translation speed, oceanic stratification, and bathymetry-induced upwelling (Tseng et al., 2010). Typhoon Kai-Tak also triggered a 30 -fold increase in surface chlorophyll $a$ concentration, sufficient to account for $2-4 \%$ of the annual new production in the entire SCS (Lin et al., 2003b). The Category 4 Typhoon Babs during October 1998 induced a monthlong $6^{\circ} \mathrm{C}$ drop at $75 \mathrm{~m}$, surprisingly larger than the corresponding drop in SST (Chang et al., 2010). Both the background ocean condition and typhoon properties (propagation speed, magnitude) could have significant impact on the typhoon-induced cooling. The strong SCS stratification could be related to the significant cooling due to the disturbance induced by the typhoon.

The ITOP experiment aims to advance typhoon knowledge to the next level by attempting to understand the three-dimensional ocean response to a typhoon, how ocean eddies affect the response, and the mechanisms by which the cold wake disappears. The ITOP experiment typifies the level of effort

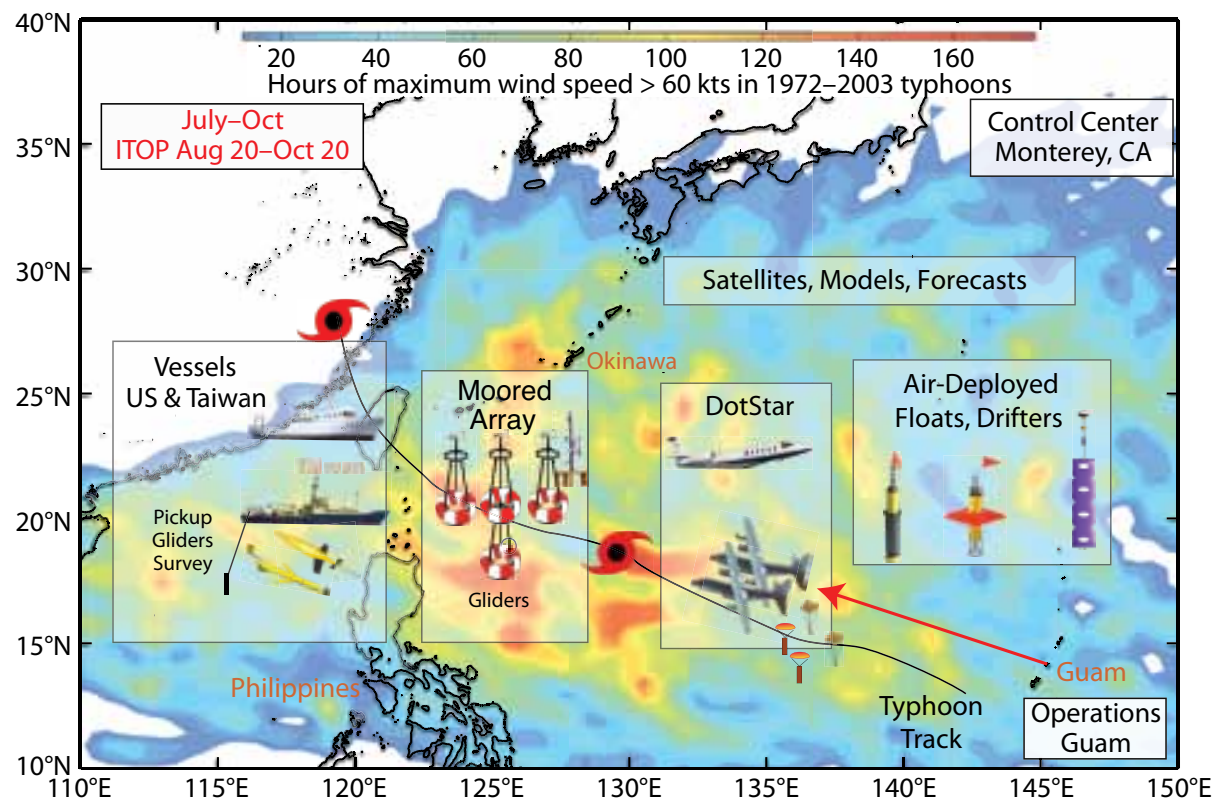

Figure 6. A schematic diagram showing the activities that took place during the ITOP experiment during July-October 2010. The colored background shows the probability of typhoon winds. Figure courtesy of Eric D'Asaro, APL/UW 


\section{REFERENCES}

Alford, M.H., R.-C. Lien, H. Simmons, J. Klymak, S.R. Ramp, Y.-J. Yang, T.-Y. Tang, D. Farmer, and M.-H. Chang. 2009. Speed and evolution of nonlinear internal waves transiting the South China Sea. Journal of Physical Oceanography 40:1,338-1,355, http://dx.doi. org/10.1175/2010JPO4388.1.

Chang, M.-H., R.-C. Lien, T.Y. Tang, E.A. D’Asaro, and Y.J. Yang. 2006. Energy flux of nonlinear internal waves in northern South China Sea. Geophysical Research Letters 33, L03607, http:// dx.doi.org/10.1029/2005GL025196.

Chang, Y.-T., T.Y. Tang, S.-Y. Chao, M.-H. Chang, D.S. Ko, Y. Jang Yang, W.-D. Liang, and M.J. McPhaden. 2010. Mooring observations and numerical modeling of thermal structures in the South China Sea. Journal of Geophysical Research 115, C10022, http://dx.doi.org/ 10.1029/2010JC006293.

Chiu, C.-S., S.R. Ramp, C.W. Miller, J.F. Lynch, T.F. Duda, and T.-Y. Tang. 2004. Acoustic intensity fluctuations induced by South China Sea internal tides and solitons. IEEE Journal of Oceanic Engineering 29:1,249-1,263, http:// dx.doi.org/10.1109/JOE.2004.834173.

Duda, T.F., J.F. Lynch, J.D. Irish, R.C. Beardsley, S.R. Ramp, C.-S. Chiu, T.-Y. Tang, and Y.-J. Yang. 2004. Internal tide and nonlinear internal wave behavior at the continental slope in the northern South China Sea. IEEE Journal of Oceanic Engineering 29:1,105-1,131, http:// dx.doi.org/10.1109/JOE.2004.836998.

Farmer, D., Q. Li, and J.-H. Park. 2009. Internal wave observations in the South China Sea: The role of rotation and non-linearity. AtmosphereOcean 47:267-280, http://dx.doi.org/10.3137/ OC313.2009.

Gawarkiewicz, G., J. Wang, M. Caruso, S.R. Ramp, K. Brink, and F. Bahr. 2004. Shelfbreak circulation and thermohaline structure in the northern South China Sea: Contrasting spring conditions in 2000 and 2001. IEEE Journal of Oceanic Engineering 29:1,131-1,143, http:// dx.doi.org/10.1109/JOE.2004.839123.

Jan, S., R.-C. Lien, and C.-H. Ting. 2008. Numerical study of baroclinic tides in the Luzon Strait. Journal of Oceanography 64:789-802.

Klymak, J.M., R. Pinkel, C.-T. Liu, A.K. Liu, and L. David. 2006. Prototypical solitons in the South China Sea. Geophysical Research Letters 33, L11607, http://dx.doi.org/10.1029/ 2006 GL025932.

Lien, R.-C., T.Y. Tang, M.H. Chang, and E.A. D'Asaro. 2005. Energy of nonlinear internal waves in the South China Sea. Geophysical Research Letters 32, L05615, http://dx.doi.org/ 10.1029/2004GL022012.

Lin, I.I., W.T. Liu, C.C. Wu, J.C.H. Chiang, and C.H. Sui. 2003a. Satellite observations of modulation of surface winds by typhoon-induced upper ocean cooling. Geophysical Research Letters 30, 1131, http:// dx.doi.org/10.1029/2002GL015674.

Lin, I.I., W.T. Liu, C.-C. Wu, G.T.F. Wong, C. Hu, Z. Chen, W.-D. Liang, Y. Yang, and K.-K. Liu. 2003b. New evidence for enhanced ocean primary production triggered by tropical cyclone. Geophysical Research Letters 30, 1718, http://dx.doi.org/10.1029/2003GL017141.

Mazzega, P., and M. Bergé. 1994. Ocean tides in the Asian semi-enclosed seas from TOPEX/ POSEIDON. Journal of Geophysical Research 99:24,867-24,891, http://dx.doi.org/10.1029/ 94JC01756.

Moore, S.E., and R.-C. Lien. 2007. Pilot whales follow internal solitary waves in the South China Sea. Marine Mammal Science 23:193-196, http://dx.doi.org/10.1111/ j.1748-7692.2006.00086.x.

Niwa, Y., and T. Hibiya. 2004. Three-dimensional numerical simulation of the $\mathrm{M}_{2}$ internal tides generated around the continental shelf edge in the East China Sea. Journal of Geophysical Research 109, C04027, http://dx.doi.org/ 10.1029/2003JC001923.

Price, J.F. 1981. Upper ocean response to a hurricane. Journal of Physical Oceanography 11:153-175.

Price, J.F., T.B. Sanford, and G.Z. Forristall. 1994. Forced stage response to a moving hurricane. Journal of Physical Oceanography 24:233-260, http://dx.doi.org/10.1175/1520-0485(1994)024 $<0233$ :FSRTAM>2.0.CO;2.

Ramp, S.R., T.Y. Tang, T.F. Duda, J.F. Lynch, A.K. Liu, C.-S. Chiu, F.L. Bahr, H.-R. Kim, and Y.-J. Yang. 2004. Internal solitons in the northeastern South China Sea: Part I. Sources and deep water propagation. IEEE Journal of Oceanic Engineering 29:1,157-1,181, http:// dx.doi.org/10.1109/JOE.2004.840839.

Ramp, S.R., Y.J. Yang, and F.L. Bahr. 2010. Characterizing the nonlinear internal wave climate in the northeastern South China Sea. Nonlinear Processes in Geophysics 17:481-498, http://dx.doi.org/10.5194/npg-17-481-2010.

Reeder, D.B., B.B. Ma, and Y.J. Yang. 2011. Very large subaqueous sand dunes on the upper continental slope in the South China Sea generated by episodic, shoaling deep-water internal solitary waves. Marine Geology 279:12-18, http://dx.doi.org/10.1016/j.margeo.2010.10.009.

Shaw, P.-T., D.-S. Ko, and S.-Y. Chao. 2009. Internal solitary waves induced by flow over a ridge: With applications to the northern South China Sea. Journal of Geophysical Research 114, C02019, http://dx.doi.org/10.1029/ 2008JC005007.

St. Laurent, L. 2008. Turbulent dissipation on the margins of the South China Sea. Geophysical Research Letters 35, L23615, http://dx.doi.org/ 10.1029/2008GL035520.
Tseng, Y.H., S. Jan, D. E. Dietrich, I.I. Lin, Y.T. Chang, and T.Y. Tang. 2010. Modeled oceanic response and sea surface cooling to Typhoon Kai-Tak. Terrestrial, Atmospheric and Oceanic Sciences 21:85-98, http://dx.doi.org/ 10.3319/TAO.2009.06.08.02(IWNOP).

Yang, Y.J., Y.C. Fang, M.-H. Chang, S.R. Ramp, C.-C. Kao, and T.Y. Tang. 2009. Observations of second baroclinic mode internal solitary waves on the continental slope of the northern South China Sea. Journal of Geophysical Research 114, C10003, http://dx.doi.org/ 10.1029/2009JC005318.

Ye, A.L., and I.S. Robinson. 1983. Tidal dynamics in the South China Sea. Geophysical Journal of the Royal Astronomical Society 72:691-707, http://dx.doi.org/10.1111/j.1365-246X.1983. tb02827.x.

Zhang, Z., O.B. Fringer, and S.R. Ramp. 2010. Three-dimensional, nonhydrostatic numerical simulation of nonlinear internal wave generation and propagation in the South China Sea. Journal of Geophysical Research 116, C05022, http://dx.doi.org/10.1029/2010JC006424. 